\title{
Achieving Energy Efficiency in Accordance with Bioclimatic Architecture Principles
}

\author{
Bujar BAJCINOVCI*, Florina JERLIU \\ Faculty of Civil Engineering and Architecture, University of Prishtina, FNA, Bregu i Diellit p.n, 10000 \\ Prishtina, Kosovo
}

\begin{abstract}
By using our natural resources, and through inefficient use of energy, we produce much waste that can be recycled as a useful resource, which further contributes to climate change. This study aims to address energy effective bioclimatic architecture principles, by which we can achieve a potential energy savings, estimated at thirty-three per cent, mainly through environmentally affordable reconstruction, resulting in low negative impact on the environment. The study presented in this paper investigated the Ulpiana neighbourhood of Prishtina City, focusing on urban design challenges, energy efficiency and air pollution issues. The research methods consist of empirical observations through the urban spatial area using a comparative method, in order to receive clearer data and information research is conducted within Ulpiana's urban blocks, shapes of architectural structures, with the objective focusing on bioclimatic features in terms of the morphology and microclimate of Ulpiana. Energy supply plays a key role in the economic development of any country, hence, bioclimatic design principles for sustainable architecture and energy efficiency, present an evolutive integrated strategy for achieving efficiency and healthier conditions for Kosovar communities. Conceptual findings indicate that with the integrated design strategy: energy efficiency, and passive bioclimatic principles will result in a bond of complex interrelation between nature, architecture, and community. The aim of this study is to promote structured organized actions to be taken in Prishtina, and Kosovo, which will result in improved energy efficiency in all sectors, and particularly in the residential housing sector.
\end{abstract}

Keywords - Energy efficiency; architecture; bioclimatic principles; environment; design

\section{INTRODUCTION}

Cities are complex ecosystems with specific phenomena, they are open integrated systems and huge organisms with specific and complex metabolisms that transform vast amounts of energy [1]. Kosovo, generally produces electricity from the coal generated power plant, the capacity of which is not sufficient to cover the needs of Kosovo. Kosovo does not have reserves of natural gas or oil, nor access to gas or oil. By 2010, the residential sector is determined the sector that consumes the most energy, currently now consuming $50 \%$ of the total energy, where the housing sector in particular relies on electricity as its primary source for heating. Moreover, Kosovo is absolutely committed to reducing energy consumption by encouraging greater efficiency in the use renewable energy resources.

As a member of the Energy Community in South East Europe, the national plan for energy efficiency has a goal set to achieve annual savings by at least $1 \%$ [2]. The residential sector is the one of the largest energy consumers in Kosovo. At the level of savings and law for energy efficiency, the Energy Act 2004/8, Article 10 [3], provides a legal basis for implementing energy efficiency, in particular: formulation, implementation, and promoting the use of energy from

* Corresponding author.

E-mail address: florina.jerliu@uni-pr.edu 
renewable energy resources. Thus, in that context: "Bioclimatic architecture has developed over many years to address the problems inherent in buildings. Through a process of trial and error our ancestors have found effective ways to handle the different climatic conditions. All through history, people were trying to adapt their buildings with the environment in order to create better living conditions" [4]. Bioclimatic design principles for sustainable architecture and energy efficiency present an evolutive integrated strategy for achieving efficiency, and healthier impact on Kosovar communities. Conceptual findings indicate that by integrating strategies related to energy, conceptual bioclimatic design of space, and premises of interactive organic architecture, a multidimensional thread between nature and urbanites is created, thus, resulting in proactive energy efficiency. The objectives of this study are actions to be taken in Kosovo, which will result in improved energy efficiency, and a healthier environment, particularly in the residential housing areas.

In Kosovo, demand for space heating represents about $65 \%$ of the energy produced in the winter season. Due to the limited available finance resources, many homes are currently unfinished; 30 $\%$ of owners will have to wait many years before they finish the entire facade or building envelope, while many of the buildings are covered with facades without thermal insulation. Hence, the aim of this paper is to address challenges that relate to urban design in relation to energy efficiency. Bioclimatic passive design principles conceptually have positive impact according to the actual state and praxis of building industry, further, the main obstacles for not implementing the most crucial actions and features for energy efficiency, on existing buildings are:

- Lack of capital investment;

- Short-term perspective from the building owner;

- Low level of awareness about the benefits of service, price/insulation;

- Lack of enforcement of building standards and materials.

According to the World Energy Council, assessment: governments, should recognize and include the size, scale, pace and needed development in the energy sector and relations with the sectors. The government must also ensure that the energy strategy and policies are appropriate to the required tasks. Coordination must be at the highest level, and ideally, one appointed ministry devoted to a particular strategy should be responsible for the management of energy and climate initiatives and for consultations with other ministries, if necessary [5]. Moreover, the common architectural design praxis, on the whole lacks integration of issues, "Our design process is such that only pieces are optimized and not the whole. Each of these professionals is designing fully within the silo of their discipline, and the interaction between each discipline is usually kept to a minimum [...] The optimization of the building's individual systems is primarily done in isolation, based on rule-of-thumb conventions that target abstract, generalized standards. These systems are then assembled into a building" [6]. In addition, "Humans from the beginning respected and valued environment in which they dwell, with emphasis in finding harmony and symbiosis between their needs and the nature, or the Umwelt. The expressions 'collective Umwelt', or 'swarm's Umwelt', should also be in accord, since an organism can hardly be modelled as a centralized system" [7].

In Kosovo, the air quality is polluted in developed urban areas and especially in industrial areas. The biggest impact on the environment is caused by Kosovo Energy Corporation power plants, the mining industry Feronikeli, and building industry Sharrcem, altogether with small capacity plants, resulting with heavy activities for energy demand in the winter season. "While air pollution is obviously a global environmental issue, there is a strong will of the Kosovar communities for sustainable awareness, aiming to live healthier. Municipality of Prishtina have a potential for urban environmental planning, and civil society actions further strengthen this objective permanently" [1]. 
Hence, the Kosovar communities are in heavy interrelation, between energy demands and public health issues. According to the National Energy Efficiency Action Plan for Kosovo [2], the household sector is the single largest energy end-use sector in Kosovo, estimated at approximately $39 \%$. This is followed by the industrial sector cca. $27 \%$, transport sector cca. $23 \%$, service sector cca. $9 \%$, and the agricultural sector approximately of $2 \%$ [2]. So, what is energy efficiency? How is this notion defined in economic terms? Energy efficiency should be considered as a strategy for accomplishing and fulfilling global performance in the use of energy with less polluted environment. Moreover, the improvement of energy efficiency will accomplish the targeted objectives to the actual and approved strategies for climate change. Hence, "energy efficiency is acknowledged as actions to achieve overall resource allocation, rather considered a goal in itself" [8]. Actually, in Kosovo, there was a study in the field of air pollution and efficiency of energy, comparing emissions of $\mathrm{CO}_{2}$ and Gross Domestic Product: "Kosovo as one of the richest countries with lignite in Europe with $95 \%$ to $97 \%$ of the electric power production from lignite and with 90 $\%$ of vehicles over 10 years old, represents one of the regions with the greatest $\mathrm{CO}_{2}$ output per GDP per unit of economic activity, as well as one of the countries with the most polluted atmosphere in Europe. In this relation, we must consider the fact that Kosovo is a developing country" [1], [9].

\section{Methodology}

The study presented in this paper investigated the Ulpiana neighbourhood of city Prishtina, focusing on urban design, energy efficiency and air pollution issues. The research methods consist of empirical observation through urban spatial zone. In order to receive clearer data and information, research is made within Ulpiana's urban blocks, forms of architectural structures, furthermore we focused more on the bioclimatic features regarding the morphology of the Ulpiana neighbourhood. The study was conducted through literature review, urban documentation and drawings. The data collected includes maps, microclimate features and attributes of space; the additional data for this paper is based on the analysis of the comparative method of the existing and preferred state of buildings, with a primary objective to promote bioclimatic design principles.

In Kosovo, it is estimated that approximately $60 \%$ of buildings are not insulated. Lack of insulation, poor insulation: windows, doors, walls or roofs, cause $50 \%$ of the energy loss, especially during demand for heating and cooling season. The high level of demand for energy brings awareness to just how necessary the actions are for energy efficiency. Investing in insulation is the most direct, simple, and effective way to save money and the family budget. Through the use of insulating materials in walls, roof-terrace, or the floors of the house, we ensure much greater thermal control for heat and coolness in the respective seasons. Consequently, losses are $26 \%$ from the roof, $15 \%$ from doors and ventilation, $18 \%$ from windows, $33 \%$ from walls, a simple fact, but scientifically: thermal insulation in buildings, is the most effective way to ensure energy efficiency.

A number of projects in the field of energy efficiency have been implemented, mainly those that provide direct measures, such as: energy auditing of public buildings, implementation of audit measures, including public lighting in the city, installation of solar panels in the University Clinical Centre campus, further on student dormitories and on some government buildings.

The Progress Report 2010-2012 [3], shows that the indicative energy saving target of $3 \%$ is accomplished. Reconstruction of buildings and modernization of heating and cooling systems provide a vast energy saving potential, increased energy efficiency. Also, more rational utilization of energy in municipalities would greatly contribute to the accomplishment of envisaged targets, especially in public city lighting systems [3]. "Energy efficiency and managing energy demand continues to be globally perceived as a top action priority with huge potential for improvement. 
As highlighted through the case studies, cost savings alone are often insufficient to stimulate the adoption of energy efficiencies or behaviours" [10].

The electricity sector in Kosovo is dominated by the Kosovo Energy Corporation, an integrated system of Kosovo Energy Corporation consists of two lignite mines, at Bardh and Mirash, and two lignite power plants: 'Kosova A' and 'Kosova B', with an overall effective capacity of $740 \mathrm{MW}$ to $840 \mathrm{MW}$, with a capacity of installed $1478 \mathrm{MW}$.

Long term coal source of energy will remain the leading fuel for generating electricity in Kosovo. Kosovo's lignite reserves are located in two large spatial basins, named: 'Kosova' and 'Dukagjini'. Geologically, lignite reserves are estimated to be about 12.5 billion tons, hence, including all categories of reserves. Table 1 presents a summary of lignite reserves, investigated and exploitable, by the location of mining zones in Kosovo.

TABLE 1. Lignite RESERVES By LOCATION [11]

\begin{tabular}{|c|c|c|c|c|c|}
\hline \multirow{3}{*}{ Reserves } & \multirow[t]{3}{*}{ Area, $\mathrm{km}^{2}$} & \multicolumn{4}{|c|}{ Reserves, million tones } \\
\hline & & \multicolumn{2}{|l|}{ Investigated } & \multicolumn{2}{|c|}{ Exploitable } \\
\hline & & $\mathrm{T}$ & $\begin{array}{l}\mathrm{t} \\
\mathrm{ce}\end{array}$ & $\mathrm{T}$ & $\begin{array}{l}\mathrm{t} \\
\mathrm{ce}\end{array}$ \\
\hline Kosova & 274 & 10091 & 2957 & 8772 & 2521 \\
\hline Dukagjini & 49 & 2244.8 & 782 & 2047.7 & 464 \\
\hline $\begin{array}{l}\text { Drenica-Fusha e } \\
\text { Skenderajt }\end{array}$ & 5.1 & 106.6 & 22 & 73.2 & 19 \\
\hline Total & & 12442.4 & 3761 & 10892.9 & 3004 \\
\hline
\end{tabular}

Kosovo's lignite has low sulphur content, and relatively good concentration of lime, calcium oxide, for absorbing a portion of sulphur during combustion process. The relationship between overburden and lignite is very favourable, a fact that makes those mines with open cast mining competitive and attractive to use. With the start of construction of the power plant 'Kosova e Re' or 'Kosova C', inevitably demands for coal will increase, resulting in direct increase of capacities for lignite production.

\section{TABle 2. Power Plant Existing CAPACITIES IN Kosova [12]}

\begin{tabular}{|c|c|c|c|c|c|}
\hline \multirow{2}{*}{ Block Unit } & \multicolumn{3}{|c|}{ Capacity of units of power plant (MW) } & \multirow{2}{*}{ Source of Energy } & \multirow{2}{*}{$\begin{array}{l}\text { Age of Power Plant } \\
\text { Structure }\end{array}$} \\
\hline & & & Efficiency Disposal & & \\
\hline \multicolumn{6}{|c|}{ Power Plant "Kosovo A" } \\
\hline Unit A1 & 65 & 58 & 0 & Coal/Oil & $1962(46)$ \\
\hline Unit A2 & 125 & 113 & 0 & Coal/Oil & $1964(44)$ \\
\hline Unit A3 & 200 & 182 & 110 to 120 & Coal/Oil & $1970(38)$ \\
\hline Unit A4 & 200 & 182 & 110 to 120 & Coal/Oil & $1971(37)$ \\
\hline Unit A5 & 210 & 187 & 125 to 130 & Coal/Oil & $1975(33)$ \\
\hline \multicolumn{6}{|c|}{ Power Plant "Kosovo B" } \\
\hline Unit B1 & 339 & 309 & 240 to 260 & Coal/Fuel Oil & $1983(25)$ \\
\hline Unit B2 & 339 & 309 & 260 to 280 & Coal/Fuel Oil & $1984(24)$ \\
\hline
\end{tabular}


Few studies have been developed on Kosovo and energy efficiency or on their capacities for sources of renewable energy. Moreover, there is a situation that allows for claims that Kosovo has little opportunities for renewable energy; in such an environmentally framework the geothermal capacities have also been completely neglected and there is considerable capacity to be explored and emphasized. Hence, a proper study on exploration of geothermal capacities needs to be made. Much more evidence is presented in the situation whereby Kosovo actually does not have a wind atlas and its wind potential remains unexplored. Furthermore, biomass has also been neglected, and the solar energy capacities have been the most controversial among energy sources. The energy sector in Kosovo will require significant investment, and financial and overall capacities will need much more support. In this environmental situation with a persisting vast energy demand, much more effort must be done to introduce sustainable development strategies in Kosovo. Therefore, there is a non-alternative for cooperative action between international sponsors and the municipalities, especially because those resources will be needed under any implemented environmental program in Kosovo [13].

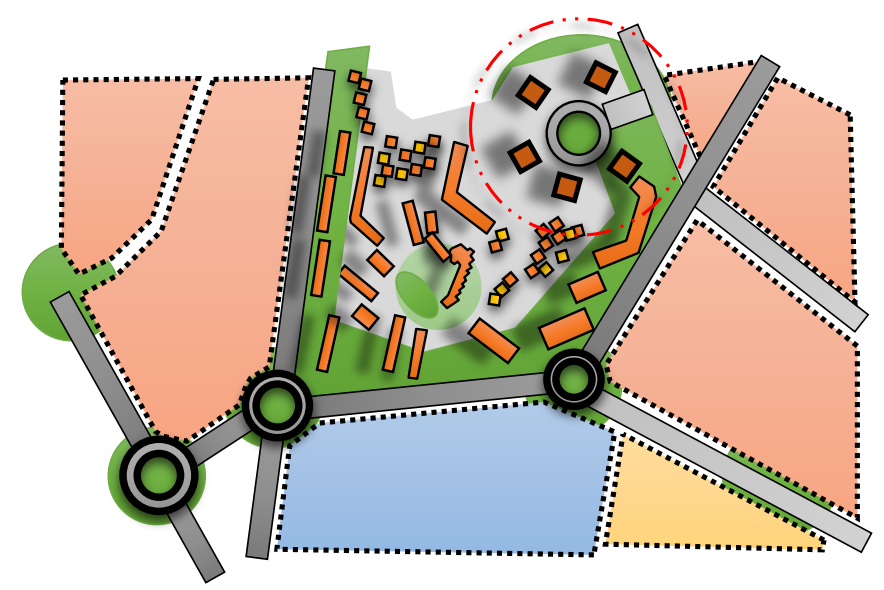

Fig. 1. Urban design of Ulpiana neighbourhood.

According to the argued and proposed energy efficiency strategy for the analysed housing unit, we can conceptually conclude that, with efficient installation of quality windows with two layers of glazing, it is possible to reduce energy use and save from $12 \%$ to $25 \%$. Reduction from airtight and efficient doors can result in saving as much as $4 \%$ to $12 \%$ of total energy use. By setting thermal insulation on the facade and exterior walls, we expect savings of $25 \%$ to $35 \%$ of the total energy use. By installing a minimum $6 \mathrm{~cm}$ thermal insulation in the roof-terrace with different materials such as Styrofoam with high density, we expect to reduce the loss of heat and save $17 \%$ to $22 \%$ [14]. Heat transmission coefficient for a multi-layer wall, can be calculated by the equation [15]:

where

$$
k=1 /\left[1 / \alpha_{\text {in }}+\sum\left(\delta_{i} / \lambda_{i}\right)+1 / a_{\text {ou }},\right.
$$

$\alpha_{\text {in }} \quad$ Coefficient of heat convection, inside of the wall, $\mathrm{W} /\left(\mathrm{m}^{2} \mathrm{~K}\right)$;

$\alpha_{\mathrm{ou}} \quad$ Coefficient of heat convection, outside of the wall, $\mathrm{W} /\left(\mathrm{m}^{2} \mathrm{~K}\right)$;

$\delta_{\mathrm{i}} \quad$ Wall thickness, layers, m';

$1 / \lambda_{\mathrm{i}} \quad$ Thermal resistance, through the layer of the air, $\mathrm{W} /\left(\mathrm{m}^{2} \mathrm{~K}\right)$. 
If we have an insulation layer with air, then it can be calculated by the equation:

$$
k=1 /\left[1 / \alpha_{i n}+\sum\left(\delta_{i} / \lambda_{i}\right)+1 / \lambda_{i}+1 / \alpha_{o u}\right.
$$

For the analysed housing unit, with actual damaged state of the wall condition, we have calculated the value of transmission coefficient, as below:

$$
k=1.66 \mathrm{~W} /\left(\mathrm{m}^{2} \mathrm{~K}\right) .
$$

Moreover, in the presented Fig. 2 and Fig. 3, we argue that analyses of energy efficiency in accordance with bioclimatic design principles for the investigated model of a housing unit, can be drastically improved and optimized. Furthermore, just for the repairing of damaged layer of insulation of Styrofoam in the researched model unit, we calculated that the heat transmission coefficient will be improved for the wall, as much as:

$$
k=0.494 \mathrm{~W} /\left(\mathrm{m}^{2} \mathrm{~K}\right) .
$$

Therefore, the bioclimatic design principles have the primary strategy objectives, as cited below:

- Achieving energy efficiency;

- Achieving bio human comfort;

- Protect and sustain the environment;

- Use and promote renewable energy sources;

- Achieving a better profit and rentable economics in the building industry.

The study was conducted in the Ulpiana's urban structure, and specifically five architectural structures, focusing on the ecological design principles, bio comfort and quality of public health. The research had an objective to survey how the Ulpiana neighbourhood responses in adopting, adapting, and implementing bioclimatic design principles. A holistic approach to the architectural design, in accordance with bioclimatic principles, can be used as a working model in finding the best possible solution for implementation of the most appropriate ecological community actions.

"Bioclimatic architecture involves looking at the big picture, shrinking the scale of the observer's perception over the construction site and resolving core problems in order to allow such manifestations to evolve naturally" [16].
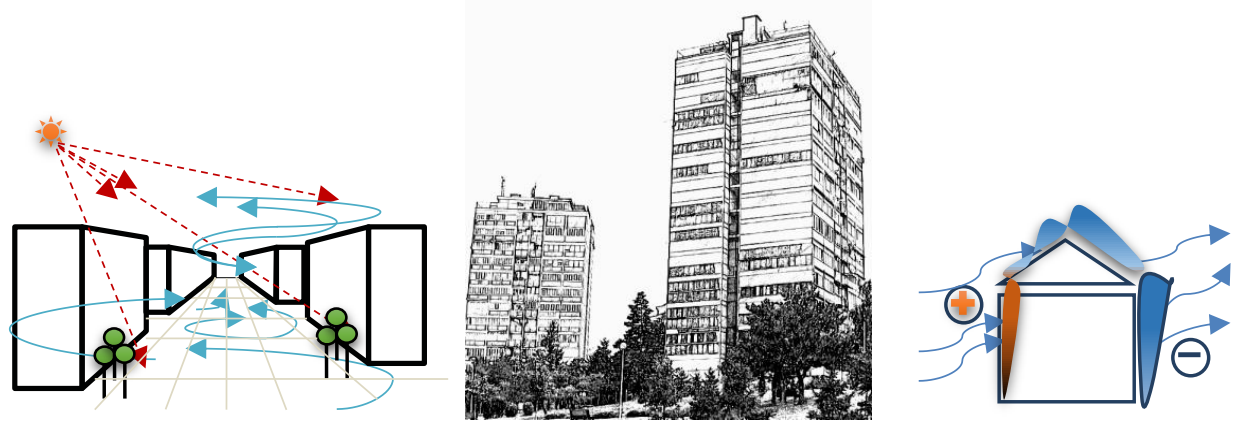

Fig. 2. Skyscraper's Ulpiana, analysed a conceptual housing unit, wind pressure-cross ventilation. 


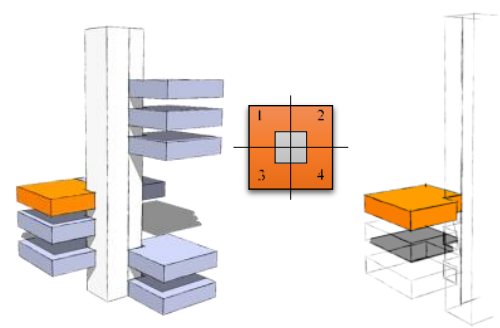

Fig. 3. Model for analysing: a conceptual housing unit, no orientation impact.

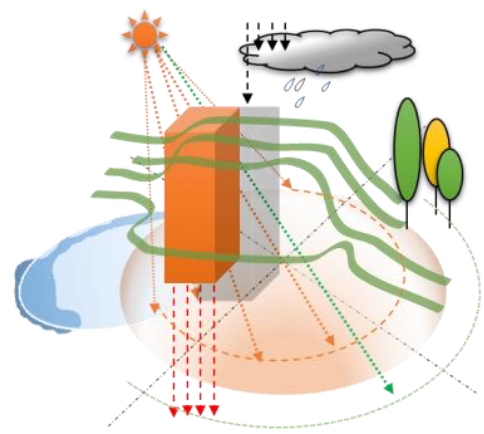

Fig. 4. Passive bioclimatic architecture design principles.

\section{DisCUSSION}

It is crucial to study, adopt, adapt and implement bioclimatic architectural design principles which will enrich efficiency and reduce overall energy consumption. "The main reason is the energy efficiency, indoor air quality and thermal comfort dilemma" [17]. For the presented case study, building floor plans were not available to the authors, therefore, drawings of the existing situation and the maps of floor plans were done after surveying the architectural structures in situ. The building construction structure was built as the 'core structural grid' with residential units distributed on four sides. The composition of the building is solid in terms of energy efficiency, hence, the perimeter of the building and the wall surfaces in contact with the external environment are in proper ratios. The structures were built by the 1970s and they do not have uniform thermal characteristics throughout the structure. The construction system is with mixed panels, with extensive retaining walls of $25 \mathrm{~cm}$, and made from reinforced concrete material.

Moreover, from surveying the site and unit structures chosen for the research, there are visible cracks on the facade, and sheets of aluminium facade and plaster are clearly felled. Hence, these examined cracks do not penetrate deep into the walls, but only in the thickness of the plaster, and this way do not endanger the stability of the building. The building had modest external thermal insulation, but it is, on the whole, totally degraded and not thermally sufficient. Even though the facade had been renovated several times through the actions of individual owners, it is clear that those actions did not solve the problem, there were also some partial works and interventions made to the colour and plaster without external insulation. Thus, in general the windows are old and not good at all, old windows made from wood frame, with thickness of $5 \mathrm{~cm}$ and single glazed. The value adopted for the calculation of windows is rounded off as $2.8 \mathrm{~W} /\left(\mathrm{m}^{2} \mathrm{~K}\right)$, although under 
'Technical Regulation for energy saving in buildings' windows, must not exceed $k=1.8 \mathrm{~W} /\left(\mathrm{m}^{2}\right.$ $\mathrm{K})$. Moreover, actually there is no institution which tests windows and doors, and certifies products with international standards. Therefore, assumed value of $2.8 \mathrm{~W} /\left(\mathrm{m}^{2} \mathrm{~K}\right)$ is adopted as a result of heavy degraded state. Parquet floors, and generally floors have not been renovated since the beginning and there is no way to provide the data of the thermal insulation layer. We assumed that such a layer does not exist, or it exists as a minimal thermal layer which is not considerable. The roof has been periodically renovated but the replacement was done only for practical seasonal emergency reasons, hence, stopping the leaking's flow, and was never intended to renovate the thermal layer in the whole structure.

\section{TABLE 3. AREA, Size AND Structure OF THE InVESTIGATED HOUSING Units}

\begin{tabular}{llll}
\hline Structure unit & Story No & Area story, $\mathrm{m}^{2}$ & Units per story \\
\hline 1 & 11 & cca: 384 & 6 \\
2 & 13 & cca: 384 & 6 \\
3 & 13 & cca: 384 & 6 \\
4 & 9 & cca: 440 & 6 \\
5 & 9 & cca: 440 & 6 \\
\hline
\end{tabular}

What are the passive bioclimatic design principles in relation to energy efficiency, and what they represent in architecture terms, or environmentally are defined? Cross ventilation is the natural feature of freshness, uses wind speed and pressure differences to circulate air. In architectural terms, those principles can be used in general situations and conditions when we address sustainable design issues, moreover, a building can greatly utilize this bioclimatic design features as sustainable strategy, resulting in saving more energy and electric bills. "In order to motivate building technicians and managers to achieve even greater energy savings, some part of the saved money is given back to the building. Up to $15 \%$ of the savings budget can be used in addition to the regular salary of the staff' [18]. Advantages of those passive methods, in the design process, and effectiveness can be multiplied accordingly in order to adapt to the microclimate. In most cases, designing and being effective means to implement both strategies, windows located on opposite sides of the building, provide the most natural ventilation breeze, and we also argue that a selected side of structures walls, painted with white colour reflect up to $70 \%$ of sunlight, and mutual, dark painted walls absorb cca. $80 \%$ of solar energy. "In Latvia multifamily apartment buildings account for more than a half of the total heated area of housing stock. In 2009 total heated area of residential buildings was 87 million $\mathrm{m}^{2}$ from which 54.5 million $\mathrm{m}^{2}$ was heated area of multi-family buildings with three and more apartments, $26 \%$ of this area belongs to the buildings built before 1940. Most of these buildings are considered as historical heritage and are under protection" [19]. Therefore, according to this study, with proper new insulation layers, renovation of the old ones, painting with a studied colour on the façade, and implementing a bioclimatic principle for cross ventilation of housing units, we expect to reduce thermal loss as much as 5 times. Respectively, with proper renovation of roofs and installing a $20 \mathrm{~cm}$ thermal layer, it is calculated to save on energy loss up to $45 \%$, or $9 \mathrm{~m}^{3}$ natural gas, a proper renovation of walls and installing a $10 \mathrm{~cm}$ thermal layer is expected to save on energy loss up to $35 \%$, or 8 $\mathrm{m}^{3}$ natural gas, with a proper action for renovation of windows and installing new windows with triple glazing is expected to save energy loss up to $20 \%$, or $4 \mathrm{~m}^{3}$ natural gas. Accordingly, a single housing unit in the case study structure with proper introduction of bioclimatic passive principles, expect to save, according to our estimations, up to $60 \%$ of used energy in one year. 


\section{Conclusion}

Researched model of one housing unit, surveyed for energy efficiency with a solid $70 \mathrm{~m}^{2}$ area, dedicated for a single-family, according to conceptual and calculated findings, with a proper implementing of bioclimatic passive principles, indicates that the energy savings can go up to $60 \%$ in a year compared to the actual state, thus saving a family's budget evaluated for one-year period, using average annual climate conditions. Hence, according to actual climate conditions we expect to abstain from heating in the period from October to November. Implementing bioclimatic strategies with cross ventilation features, we expect to gain savings in energy for cooling, from May to June and from September to October. In the summer season by implementing a total renovation to a surveyed structure, through painting a facade with a light colour and gaining from nearby vegetation freshness and cooling breeze we expect to gain some considerable savings for air-condition or mechanical ventilation. Based on the presented findings, strengthened with the best practices of literature review and World Bank Group studies, we recommend implementation of the bioclimatic passive principles, hence, from conceptual recommendations of this study, more specifically we recommend:

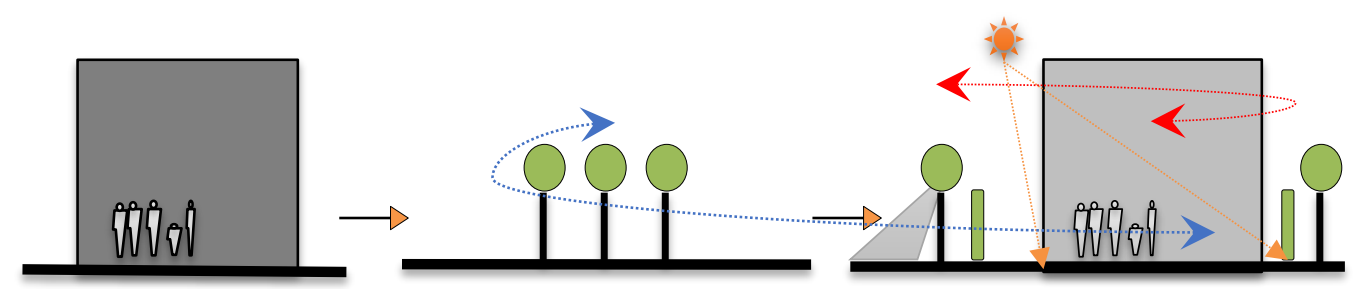

Fig. 5. Model a) and b). Differences in use of microclimate features with bioclimatic design principles, energy efficiency.

- Adopting, developing and documenting monitoring, reporting and evaluation procedures, as well as sustainable approaches in the urban and architectural energy efficiency design;

- By incorporating the new design strategies in the existing legal guidelines, it is expected to have a significant positive impact in the community by raising the quality of life and energy efficiency in Prishtina.

Architectural structures have a very long existence, and surely the power system will change substantially in the coming decades. Politicians and decision makers should have knowledge about how energy efficiency can contribute to reduce greenhouse gas emissions in their life span [20].

\section{REFERENCES}

[1] Bajçinovci B., Jerliu F., Challenges of Architectural Design in relation to Environment and Air Pollution. A Case study: Prishtina's first public parking garage. Journal of Science, Humanities and Arts 2016:3(7). doi:10.17160/josha.3.7.254

[2] Kull K. On Semiosis, Umwelt, and Semiosphere. Semiotica 1998:120(3/4):299-310.

[3] Dennis K. The Compatibility of Economic Theory and Proactive Energy Efficiency Policy. The Electricity Journal 2006:19(7):58-73. doi:10.1016/j.tej.2006.07.006

[4] Qatar Green Building Council. Bioclimatic principles towards sustainable, comfortable and energy efficient societies. Presented at 2nd Qatar Green Building Conference, Doha, 2015.

[5] World Energy and Climate Policy: 2009 Assessment. World Energy Council. London: 2009. www.worldenergy.org [Accessed 10.08.2016].

[6] 7Group, Reed B. The integrative design guide to green building. Hoboken: Wiley and Sons, 2009. 
[7] MEM. Ministry of Economic Development. National Energy Efficiency Action Plan of Kosovo. Kosovo, 2013.

[8] Kabashi S., et al. Effects of Kosovo's energy use scenarios and associated gas emissions on its climate change and sustainable development. Applied Energy 2011:88(2):473-478. doi:10.1016/j.apenergy.2010.06.023

[9] MEM. Ministry of Economic Development. Kosovo. Energy Strategy 2013-2022, 2013.

[10] World Energy Council. World Energy Trilemma 2016: Defining measures to accelerate the energy transition, 2016.

[11] INKOS. Assessing and exploring geological coal reserves in Kosovo, 2007.

[12] KEK. Kosovo Energy Corporation. Report, Kosovo, 2008.

[13] KOSID. A Policy Solution for the Energy Sector in Kosovo. Prishtine: 2014.

[14] INDEP. Energy efficiency. Prishtine: 2015:3-4.

[15] Fejzullah K, Selimaj R., Malsiu I. Instalimet Makinerike. Universiteti i Prishtinës. Prishtinë, 2004.

[16] Tudrea H., Budescu M. Bioclimatic Architecture, a sensible and logical approach towards the future of building development. Buletinul institutului politehnic din Iaşi, Romania, 2013.

[17] Asere L., Mols T., Blumberga A. Assessment of Energy Efficiency Measures on Indoor Air Quality and Microclimate in Buildings of Liepaja Municipality. Energy Procedia 2016:95:37-42. doi:10.1016/j.egypro.2016.09.009

[18] Dzene I., Polikarpova I., Zogla L., Rosa M. Application of ISO 50001 for implementation of sustainable energy action plan. Energy Procedia 2015:72:111-118. doi:10.1016/j.egypro.2015.06.016

[19] Miezis M., Zvaigznitis K., Stancioff N., Soeftestad L. Climate Change and Buildings Energy Efficiency - the Key Role of Residents. Environmental and Climate Technologies 2016:17:30-41. doi:10.1515/rtuect-2016-0004

[20] Graabak I., Bakken B. H., Feilberg N. Zero Emission Building and Conversion Factors between Electricity Consumption and Emissions of Greenhouse Gases in a Long-Term Perspective. Environmental and Climate Technologies 2014:13:12-18. doi:10.2478/rtuect-2014-0002
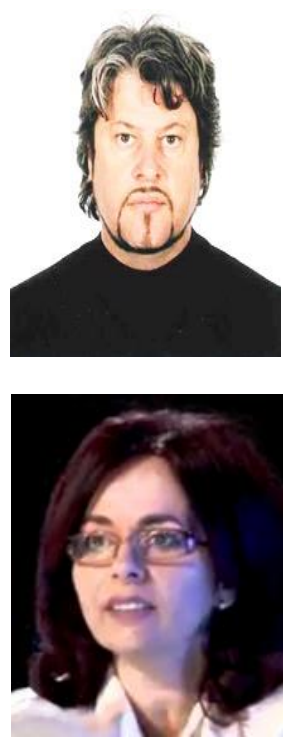

Bujar Bajçinovci received a $\mathrm{PhD}$ grade on Technical Sciences in the field of architecture and urbanism from the Faculty of Architecture, University of Sarajevo, BiH (2012), and a Diploma in Architect Engineer from the Faculty of Civil Enginering and Architecture, University of Kosovo (1991).

He currently is the Lecturer of the architectural design in the Faculty of Civil Enginering and Architecture, University of Kosovo. His research interests focus on the field of sustainable architectural design, energy efficiency, renewable energy in building sector, and environmental pollution impact to the public health.

Memberships: International Academy of Sciences, Humanities and Arts. IASHA. Freiburg, Germany. Reviewer of the Journal of Sciences, Humanities and Arts, JOSHA, Germany.

E-mail: bujar.bajcinovci@uni-pr.edu

Florina Jerliu received a degree of Diploma in Architect Engineer from the Faculty of Civil Engineering and Architecture, University of Prishtina (1996), a Masters in arts from the Faculty of Arts, University of Prishtina (2003), and the PhD in architecture and urbanism from the University of Sarajevo (2014). She holds a position of assistant professor at the Faculty of Civil Engineering and Architecture, University of Prishtina, and is also active in the professional practice. She is a co-founder and chair of the foundation for architecture and urbanism Archis Interventions Prishtina, and a co-founder and member of the Board of think-tank Kosovo Stability Initiative. Her research activity addresses the architectural urban phenomena of cities in transition.

She chaired the Kosovo Association of Architects (2003-2008), was member of NALAS (Network of Associations of Local Authorities in Southeastern Europe) Task Force for Urban Planning (2009-2014), member of Advisory Board for Urban Planning and Development in City of Prishtina (2009-2011). As of 2015, she is a member of the Board of the Kosovo Institute for the Protection of Monuments, and the Advisory Board of Austrian-Kosovo Society.

E-mail: florina.jerliu@uni-pr.edu 